\title{
Online Research for the Impact of ICTs on Greek Women's Employability and Entrepreneurship
}

\author{
https://doi.org/10.3991/ijac.v10i1.6818 \\ Marios A. Pappas* \\ National Center for Scientific Research "Demokritos”, Agia Paraskevi, Attica, Greece \\ mpapdit.demokritos.gr \\ Athanasios S. Drigas \\ National Center for Scientific Research "Demokritos", Agia Paraskevi, Attica, Greece \\ dr@iit.demokritos.gr \\ Yannis Papagerasimou \\ National Center for Scientific Research "Demokritos", Agia Paraskevi, Attica, Greece \\ ypapa@iit.demokritos.gr \\ Helen Dimitriou \\ National Center for Scientific Research "Demokritos", Agia Paraskevi, Attica, Greece \\ lena.dimitriou@yahoo.com \\ Maria Giannacourou \\ National Center for Scientific Research "Demokritos", Agia Paraskevi, Attica, Greece \\ m-giannadotenet.gr \\ Nadia Katsanou \\ National Center for Scientific Research "Demokritos", Agia Paraskevi, Attica, Greece \\ nadia.katsanou@gmail.com \\ Sofia Papakonstantinou \\ Creative Thinking Development, Rafina, Greece \\ spapakon@hotmail.com \\ Evangelia Daratsanou \\ Creative Thinking Development, Rafina, Greece \\ edaratsanou@gmail.com \\ Christina Agoritsa \\ General Secretariat for Gender Equality, Athens, Greece \\ xragoritsalisotita.gr
}

Abstract-Due to the increasing demands of highly skilled employees on ICT, European industries could face shortage of employees in the ICT sector. In the existing problem of lack of ICT executives in the European labour market it is added the problem of low representation of women in jobs related to ICT. In Greece this problem is even more intense as a result of the economic conditions 
in the last six years. Our online research for the impact of ICT on Greek women's employability and entrepreneurship revealed that women overwhelmingly recognize that the field of digital entrepreneurship is one of the most important indicators of success in the $21^{\text {st }}$ century economy, as well as that there are large gaps and mismatches between the supply and demand for ICT skills. Women believe that they are under-represented in the ICT sector and there is a genderbased gap in both ICT professionals and new occupations associated with new communication technologies. The problem of under-representation of women in the ICT sector, highlights the need for design and implementation of actions which will enable the female population in training and participation in entrepreneurship and employment with focus on ICT.

\section{Introduction.}

As the world becomes more digital, so does the economy. In the near future, all businesses will have a digital footprint. The main reason is that digital technologies can help companies reach a wider audience. But technology has a lot more to offer since being the key for business growth. Technology can help a business increase efficiencies, reach new customers, reduce cost, be more agile, flexible, and in other words be more competitive.

For example, cloud computing can offer organizations, both big and small, the opportunity to scale their computing resources whenever they deem it necessary. This is done by either increasing or decreasing the required resources, meaning they are not paying for resources which they are not utilizing. The same holds true for data analytics that enable companies to analyze all data relating to their customers and the market sector in which they operate. As this data contains a wealth of information concerning the brand, products, customer service satisfaction and customers' preferences help companies to make better informed decisions regarding many areas of their business.

Thus, by helping entrepreneurs implement new technologies we can facilitate prosperity not only in individuals and firms, but also support regional and state development.

However, the implementation of new technologies requires skilled personnel which reports show that are missing. In Europe, most of the EU Member States have made substantial improvements over the past decade at the level of macroeconomic skills mismatch, also through upskilling of their population. However, in Greece a strong deterioration in labour market outcomes, as a result of the crisis, has led to a worsening of skills mismatch.

\section{The "e-Women" project.}

The purpose of the "e-Women" project is to determine the current state of the art of the participation and awareness of women, particularly young women in ICT and the benefits arising from their use in the field of employment and entrepreneurship. The project will focus on exploring how social networks and internet can combat em- 
ployment inequalities and promote new opportunities for entrepreneurship and selfemployment of women, especially young.

The project involves the detection and evaluation of the existing possibilities provided by digital tools, as well as professional, educational, social networking platforms and e-learning. A parallel research will analyze the current use of the internet for employability purposes and awareness of young women in Greece.

The aim of this study is to conduct:

- A research on the impact of ICT, social networks and media on the creation of new employability paths (research on the labor market for job opportunities through internet).

- A research on social and bender equality aspects, security of social networks for women, women's empowerment and e-mentoring techniques.

- A research on the possible ways for the adaptation of traditional economic practices with internet capacities and social media.

The "e-Women" project aims also to share experience, knowledge and skills on trends in employment paths for women and in supporting them to proactively take their future and carrier in their own hands, to gather inspiration from good experiences, exchange and share experiences and guidance, even from other countries (inside and outside Greece, i.e. Greece and Norway) and to identify, analyze and explore different concepts and new technologies leading to new forms of knowledge and employment opportunities for women

Furthermore, the project refers to the configuration and presentation of the general framework of research (literature research and online survey) based on previous studies and research, design and conduct of qualitative research through personal interviews with persons who belong to the parties involved and finally the reference for cognitive and social research on the use of ICT.

\subsection{Questionnaire}

Within the project, a questionnaire was prepared, containing specific questions about the new necessary ICT skills and the role of women in relation to these skills, as well as the opportunities provided by the utilization of ICT. The questionnaire was forwarded online from June 29 to October 2 2016. In order to establish the appropriate questionnaire, the following actions were preceded:

1. Identification and specialization of the research objective.

2. Literature review for the selection of characteristics (variables) to be controlled.

3 . Selection of the data collection method.

4. Understanding the characteristics of respondents.

The survey covered a sample of the female population of Greece, from the age of 16 and above ( $93.6 \%$ of the participants were between 16 and 44 years old). For the purpose of the research, we used simple random sampling in women who had at least basic knowledge of MS Office, as the questionnaire was administered and answered 
electronically. We also sought an evenly distributed participation of the whole Greek territory. In order to obtain the data, we used structured questionnaires with closed questions (dichotomous, calibration and multiple choice) and only a few open type questions.

Before the questionnaires were administered, a pilot questionnaire was used in order to ascertain whether the terms used were easily perceived, the order of questions could cause distortion, the way of drafting the questions allowed the collection of desired data and whether the questionnaire was not particularly extensive, causing disinterest. The questionnaires were sent massively via e-mail while posted at the same time posted to social media (Facebook, Linkedin, Twitter and Foursquare). The goal was to collect answers from at least 1,000 questionnaires, which were collected and gave the data for the analysis. From the women Participated, $71.8 \%$ resides in Athens, $4.1 \%$ in Thessaloniki, $15.1 \%$ in other cities in Greece, while $2.2 \%$ lives outside the Greek territory. $61.5 \%$ of women were employees, $19.8 \%$ were unemployed and $12.1 \%$ were entrepreneurs.

\subsection{Interview}

This method is in the center of qualitative research, concerning the direct communication between interviewer and interviewee and enables the researcher to listen carefully, gather essential information and experiences and to analyze appropriately for the research purpose. For the purpose of this study we chose the method of direct, in depth, structured interviews.

\section{$3 \quad$ Results}

\subsection{Women's employability and ICT.}

Employability is commonly defined as the combination of factors and processes that enable people to progress toward or find employment, to remain employed, and/or to advance in the workplace and as such employability emphasizes an individual's skills and skill development. The popularity of this concept has grown as global business has moved away from a workforce based on long-term tenure in favor of shorter-term, transitory arrangements. The employment trend today is that employees usually stay a few years at a job in contrast to past generations in which employees used to spend entire careers with one company. In addition, employability represents a conceptual and policy shift away from collective workforce approaches, such as full employment, and toward individual employee assets. With technology skills and processes at the heart of economic transactions, ICT training is closely connected to employability, upward mobility and higher compensation schemes. These themes were investigated through the survey questionnaire.

Gender Perceptions Regarding ICT skills: Although the majority of the responders 56,2 believe that there is no differentiation between genders regarding ICT skills, showing a quite high level of confidence and self-efficacy in digital skills, in 
the following questions, a large percent $(38,6 \%)$ believes that men are more knowledgeable than women. It seems that although gender role and expectations stereotypes are changing, some gender polarization still exist, evident in the perceptions of a large group of participants.

Most studies recognize that differences between men and women in use of and attitudes toward ICT stem from gender role socialization. Gender identity is formed through a process by which societal norms and attitudes are internalized. It seems that many men and women still regard computers as a male rather than a female, or common domain, preventing or steering away women from this field.

In addition, other studies show that women have low self-confidence believing that learning and working with computers are difficult tasks, and that computers are in "the masculine domain", a fact that might influence motivation and retention of women in the Computer and Information Science.

Studies on self-efficacy models of motivation suggest that women's beliefs about their ability to succeed at a learning task are more important that their actual skill levels or the difficulty of the task (Cross \& Steadman, 1996). Thus, it is important to motivate women to increase their skills and knowledge in what still, a lot of them, perceive as a male dominated domain.

Upward Mobility: The contradicting responses regarding women's access in managerial and decision making positions (51\% vs $49 \%)$ reveal women's indecisiveness regarding this variable. Fifty-one percent of the participants believe that women face no difficulties in upward mobility, while $49 \%$ believe that women do face difficulties. It is interesting that unmarried women and those belonging to the 25-34 and $35-44$ age groups seem to believe more strongly that women are not promoted to the high managerial and decision making positions at the same rate as their male counterparts. A possible explanation could be found in the drive for career advancement that these groups are exhibiting. Regarding the age effect, although late twenties up to early forties are considered as the most productive years, family - career compromises are starting to take their toll. Thus, the impenetrable barriers between women and the executive suite could be experienced more strongly by women belonging to these groups as lack of career opportunities.

Despite a dramatically growing presence in the workplace, women remain underrepresented in management positions in business as artificial barriers, generally known as the "glass ceiling" effectare inhibiting their advancement. Literature review has shown that upward mobility seems to be influenced by a variety of factors, such as:

- Labor market and organizational characteristics,

- Gender roles and in particular balancing both motherhood and career obligations,

- The reluctance of men to accept women in management because of stereotypes, and their exclusion from powerful male networks, and

- Personal traits that are considered necessary for managerial success.

It seems that because of the complexity of factors influencing women's workplace advancements, for which the term "labyrinth" has been recently suggested (Guerrero, 2011 , p. 382) indicating the complicated, exhausting challenges that women must 
navigate on their way to senior roles, the evidence from the survey is mixed and inconclusive since the women's responses are split almost equally into the two categories.

Barriers to Upward Mobility: Participants seem to attribute difficulties in accessing higher rank positions mostly in stereotypes and male attitudes, which are compatible to literature findings.

A major barrier to women's progress in management worldwide, according to several studies, continues to be the gender stereotyping of the managerial position. Schein (2007) in an overview of women in management worldwide states that the persistent stereotype that associates management with being male is the most important hurdle for women in management in all industrialised countries.

Occupational stereotypes are clusters of assumptions about the sorts of activities and interests that are associated with the roles of men and women in society. Gender segregation creates a set of jobs which are considered as appropriate for men or women and this affects perceptions of performance based on the masculine or feminine attributes that best fit the role. Occupational gender stereotyping is important to consider because of labour market outcomes especially in terms of recruitment, hiring, pay, and promotion that may result from them. Further, gender stereotyping of occupations may discourage individuals from pursuing careers in occupations typed as gender-inappropriate for them, even though they may actually be well-suited for such careers.

There are also studies which show a tendency by men to describe women managers as less self-confident, less emotionally stable, less analytical, less consistent, and having poorer leadership abilities than male managers influencing thus their attitudes towards female managers (Stroh et al. 1996, Chuang, 2003). Such beliefs lead to assumptions that contribute to negative stereotypes. These assumptions may include statements such as: women tend to place family demands above work considerations, or that women work for supplemental income and as a result, they lack the necessary drive to succeed in business, women are too emotional, etc. Such assumptions, despite if they are true or not, do not take into consideration women's conscious choice to pursue a managerial career thus making injustice to individual preferences and efforts.

The second most popular answer in the survey regarding barriers in female upward mobility is the attitudes of men, although the percentage is not very high $(9 \%)$. A possible explanation could be, despite the myriad of different barriers stated by women, that it is difficult to isolate "male attitudes" from general gender stereotyping. However, it could also signify that nowadays sexism has become more elusive than in the past (Barreto, et al. 2009) making it difficult to promptly identify it. Even when individuals personally agree with and adopt equal and fair practice, they can still harbour subconscious sexism. "The result is that prejudice is often expressed outside a person's awareness, even when people are subjectively convinced that they do not endorse prejudicial beliefs or are trying hard not to express them" and this might explain the low but visible percentage of women's answers regarding male attitudes.

Skills for Employability: Regarding skills prioritization, digital skills are considered as very important by $69 \%$ of the participants. This finding is compatible with the literature review since many studies (Felstead, Gillie, \& Zhou, 2007; Riley, 2007) 
reveal the relationship between ICT skills - employability and especially on the effect of computer skills on compensation and opportunities for upward mobility. Participants noted as key skills ICT management, teamwork, communication skills, problem solving skills, and interpersonal skills. Less important skills seemed to be the business architecture, interpretation of numerical data and operations planning.

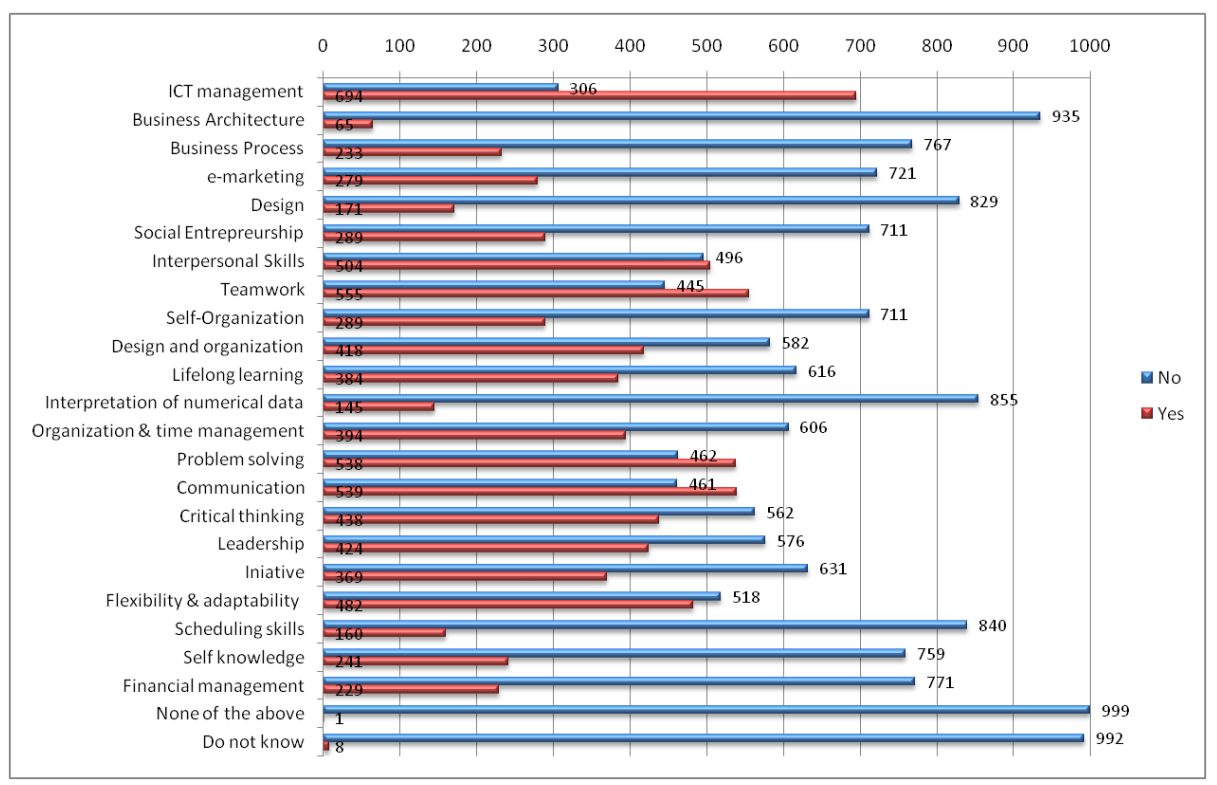

Fig. 1. Skills for women's employability

Most industries and sectors recognize that as they become increasingly digitalized, there will be more demand for staff in general to have digital skills to varying degrees. The UK forum for Computing Education (UKforCE, 2014) took as its starting point the view that 'every business is a digital business', and that the people in most professions and technical jobs will require some degree of digital skills in the next 2-3 years.

In addition, it was presented that the vast majority of the workforce will soon need basic digital skills named as 'digital citizenship skills', in order to use digital technologies when searching for information and purchasing goods and services online.

The importance of digital competence was recognized by the European Parliament and the European Council in 2006 in its recommendation on key competences for lifelong learning when it identified digital competence as one of eight key competences essential for all individuals in a knowledge-based society.

Digital competence can be defined as follows:

"Digital competence involves the confident and critical use of information Society technology (IST) for work, leisure, learning and communication. It is underpinned by basic skills in ICT: the use of computers to retrieve, access, store, produce, present 
and exchange information, and to communicate and participate in collaborative networks via the Internet."

Many European reports also reveal that although we live in a digitalized world and that countries have become better at adopting new technologies, they are getting worse at putting them into widespread use, limiting thus any possible benefit. Despite however, the importance attributed to ICT skills by survey participants, basic digital skills and usage as well integration of digital technologies are still quite low in Greece.

\subsection{Female entrepreneurship and ICT}

Gender Differences in the Capacity for Entrepreneurship: Survey participants believe that women are equally capable to men in owning and leading businesses and believe that women possess the characteristics necessary to be business leaders. An interesting finding is that younger women belonging to the 16-24 age group believe the same, but to a lesser degree showing that stereotypes are less challenged among young and inexperienced women.

However, there is a mismatch between participants' beliefs on women entrepreneurship regarding women's ability to succeed in entrepreneurship and actual data. Despite the growing recognition of the vital role women entrepreneurs play in boosting economic productivity and growth, the ratio of female entrepreneurs is quite low in comparison to their male counterparts, thus making for a huge equality gap.

According to the statistical data from the project Women Entrepreneurs in Europe carried out for DG Enterprise and Industry of the European Commission published in 2014 it was reported that in the year of the study (2012), around 30\% of all entrepreneurs in Greece were women compared to $31 \%$ in the EU-28. The vast majority of these women entrepreneurs $(82 \%)$ were solo entrepreneurs. Women entrepreneurs constituted about $24 \%$ of the women in the active labor force (entrepreneurship rate). This was significantly higher than the EU-28 average entrepreneurship rate $(10 \%)$. The proportion of men entrepreneurs of men in the active labour force in Greece (37\%) was also significantly higher than the EU-28 average.

Most women entrepreneurs in Greece work full-time. In 2012, about $11 \%$ of all women entrepreneurs worked part-time in their enterprise and this percentage was significantly lower compared to the EU-28 average (30\%).

Female Entrepreneurship in ICT: The number of women entrepreneurs in areas that require ICT skills is low compared to other sectors. According to the results, $76.8 \%$ of respondents consider that the number of women entrepreneurs in sectors that require ICT skills is low. Although women believe that they are capable as men to lead a business, very few choose to start a business in the ICT sector. Studies show that the ICT industry is still male dominated and women feel intimidated to enter in this industry (Berg et al., 2002). Women in Europe represent around 33\% of total graduates in science and technology and around $32 \%$ of employees of the ICT sector (Women Active in ICT Sector, 2013). Women represent only 19.2\% of all entrepreneurs in the ICT sector, in Europe, while they represent $53.9 \%$ of entrepreneurs in the non-ICT service sectors and constitute $31.1 \%$ of all European self-employed (all sec- 
tors). From all self-employed women in Europe, only 2\% work in the ICT sector, while $3.5 \%$ of self-employed men work in the ICT sector.

Due to the traditional position that still women in Greece occupy, some women believe that women are uninvited in the ICT sector, to the point that some participants in the focus groups use terms such as "vertical segregation" between genders or even "stigma". Studies also show that women do not give themselves enough credit, since they undervalue their ability and intellect while men overstate them. Thus, it seems that there are cultural beliefs which consciously or unconsciously exclude women from entering this field. Although there seems to be a correlation between a STEM education and employability in the tech sector, there are examples showing that success in the technology industry doesn't really require a technical degree as CEOs in tech firms such as Oracle, Hewlett-Packard or the Chief Operating Officer of Facebook suggest. All of them had degrees in law or economics.

Importance of Digital Entrepreneurship: The vast majority of the sample $(90.1 \%)$ states that digital entrepreneurship is among the most important success indicators in 21 st century economy. From the literature is evident that in addition to the economic facts, i.e. lower project costs, diverse teams in tech companies exhibit better performance regarding creativity, innovativeness, time management, but also it seems that digital technologies are practical and tangible tools for women to overcome longstanding inequalities. ICT can help women to gain employment through telework or newly created information jobs, obtain cost-effective health services and education (such as through online courses or software-based literacy programs) and to increase their income (such as through e-business channels and online transactions).

Thus, ICTs and digital entrepreneurship are important for women because they:

- offer a new field which is more open for female access than other fields

- require less resources in cash and physical terms than traditional alternatives for women

- empower home-based operation, leading to cost savings and to better family-work life balance

- enable "invisibility", thus preventing gender stereotypes

- provide a route to further personal development and growth via e-learning and via participation in eBusiness, and

- provide a route to develop more than one business, to participate in the development of different types of business and to find more easily than traditional means.

However, women seem to be at a disadvantage to benefit from the digital revolution because they are less tech savvy, according to the longstanding argument that technology is gendered (Lohan and Faulkner, 2004; Puente, 2008), and more technophobic, and because the technology is not built for their needs and intuition. In addition, it is possible that the increasing socio-economic importance of ICT could add a new dimension to the already existing vicious circle between discrimination and women's backwardness, which can be expected to be particularly severe in the near future taken into consideration the advances in technology.

Entrepreneurial Skills: Skills emerged as important for entrepreneurship in the 21 st century include innovation and vision /imagination, organizational skills, creativ- 
ity, the ability to negotiate, resourcefulness and initiative. Thus, it seems that the women participating in the survey place more emphasis on skills that will help them enter the job market, such as vision and creativity, as well as those that will help them develop and maintain a business such as organizational skills, bargaining skills and initiative. Although the 3 competence areas are tightly intertwined, the refraining of the sample participants in addressing specific resources such as personal skills (selfawareness, self-efficacy, motivation and perseverance may indicate that women do not feel less capable to develop entrepreneurial projects. This is a recurring finding in women's answers in previous questions in this survey: women again and again state that they are no gender differences regarding entrepreneurial abilities, attributing any observed differences in cultural attributes. The selection of skills most commonly associated to the entrepreneurial activity, such as the identification of opportunities is similar to that of their male counter parts.

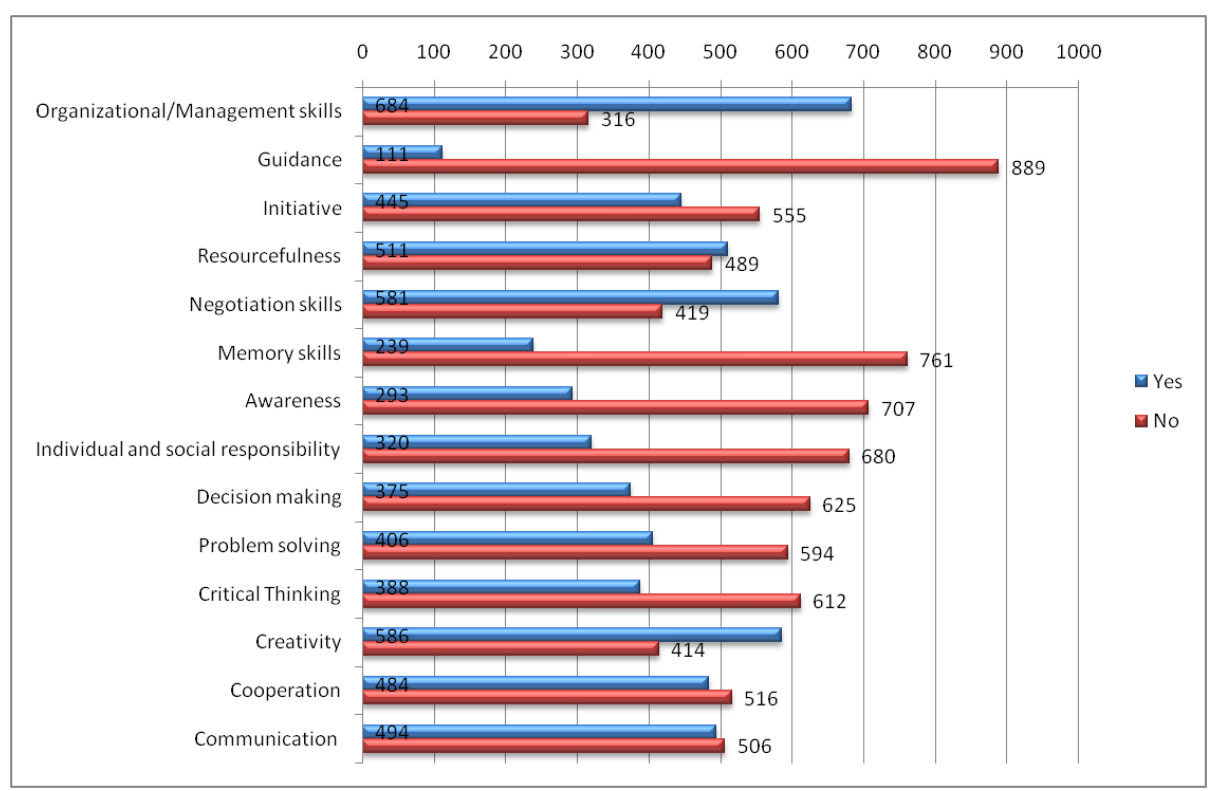

Fig. 2. Entrepreneurial Skills

However, entrepreneurship has a gender bias, women being less active in this task than men.Traditionally and historically, the figure of entrepreneur was male and therefore it emphasizes more skills and abilities that society believe are inherent to men. This could be one of the reasons that, when the profile of the perfect female entrepreneur is outlined, it includes characteristics mostly attributed to men, implying that gender stereotypes may still have an important role.

However, recent studies seem to show a change in the perceptions of which are the skills and abilities that a successful entrepreneur should possess, allowing for abilities more specific to women, such as perseverance, social and relational abilities such as empathy or social sensitivity, or abilities related to dealing with people and 
communication. These abilities and skills are an advantage over the characteristics of the male norm, as they are facilitators of the development of entrepreneurship, but also considered as demanded in the labour market

\subsection{Gender Differences in ICT}

The majority of the sample participants $(54,4 \%)$ believe that women are not equally motivated to men in attaining studies in science, technology, engineering, and mathematics (STEM) fields and sixty-eight percent (68\%) state that there exists a gap between genders regarding ICT professionals. Unmarried women and younger women (16-14) feel more strongly this lack in motivation and the existence of the gap. These findings mirror the fact that although the gender gap has narrowed in recent decades, women remain underrepresented in STEM fields. One of the most prominent explanations points to a sense of incompatibility or mismatch between being female and succeeding in STEM. In Greece, according to PISA 2015 findings boys seem to perform better in science than girls, a trend evident in most OECD countries.

Almost seventy eight percent of the women in the sample believe that women are under-represented in the ICT sector, with younger women (16-24) stating more strongly this belief, attributing the low participation of women in the ICT sector in social stereotypes and the perceptions of male dominance in the sector.

The majority of the sample $(56,3 \%)$ states that women have different attitudes than men regarding computers. An interesting finding is that women with higher education (university or post graduate degrees) seem more convinced than women with lower education. Thus, gender discrepancy does not seem to diminish over time as students gain experience with computers. There is a number of empirical studies showing that men tend to perform better and hold more positive attitudes toward computers than women. Evidence from a study conducted in Greece among 165 freshman students show also that male students are more positive in the idea to use computers than women (Bebetsos and Antoniou, 2009).Computers appear to be perceived primarily as a masculine technology, and this tends to be confirmed by the distribution of genders in computer classes. Possible explanations could involve innate gender capabilities, attitudes regarding the importance of computers, or involvement/familiarization.

\section{Conclusions}

If we try to identify the main challenge areas for the improvement of digital skills and the main findings, according to EU and OECD relevant policies, we should focus on:

1. Education and Vocational Training,

2. Women \& Girls as Digital Citizenship,

3. Female talent on labour force, and

4. Women and Girls as ICT professionals. 
Below is an overview of the corresponding policies and the focus challenges identified above focusing on the situation in Greece, as it is evident through the analysis of statistical data and reports.

\subsection{Education and Vocational Training}

Given that boys and girls come from all kinds of backgrounds and attend all kinds of schools (at least in countries where participation in schooling at age 15 is universal), differences in their self-reported experience with computers do not reflect material constraints, but rather students' interests and families' and educators' notions about what is suitable for them (see also OECD, 2015). Parents, for instance, may place more restrictions on girls' use of the Internet out of safety concerns. Literacy Study (ICILS) show that in almost all participating countries, girls in the eighth grade feel less confident than boys in their ability to do advanced ICT tasks, such as building a webpage (Fraillon et al., 2014). Greece lacks on early exposure to computers by gender as it reports the relevant figure from OECD (2015).

Tertiary education has expanded worldwide to support the supply of highly educated individuals and meet rising demand. Policy makers are particularly interested in the supply of scientists and engineers because of their direct association with technological progress, industrial performance and economic growth. Over the last period of growth in higher education participation, the gender gap has narrowed slightly with women accounting for $35 \%$ on average of all NS\&E graduates in 2012, with shares ranging from $14 \%$ in Japan to $45 \%$ in Italy. But despite the fact that Greece ranked as the fifth worst position according to the previous figure, according to the OECD statistics (2015) is one of the top five in Tertiary education graduates in natural sciences and engineering.

Training helps to improve and maintain the human capital of firms by endowing workers with the skills and knowledge needed to perform on the job and adapt to change. Training also increases the productivity of workers and thus enhances the performance and productivity of firms. While the percentage of workers receiving onthe-job training is comparatively higher in large firms in all the economies considered, the percentage of value added invested in training is generally higher for micro and small and medium-sized companies than for large enterprises. While progress is being made in modernising our education and training system, it is still very much a patchwork. While in some countries and schools there are high levels of equipment, skilled teachers and modernised curricula, it is not the case everywhere. Indeed, on the basis of the last available data only $20-25 \%$ of students in Europe are taught by digitally confident and supportive teachers having high access to ICT and facing low obstacles to their use at school. Additionally, new educational tool raised with the ICT evolution. On line courses such as MOOCS becomes important as a LLL tool. However, Greece is lagging comparing to EU average. 


\subsection{The Digital Citizenship}

Citizens need digital skills for more and more aspects of their lives. Yet still too many people do not have the basic skills they need to succeed in an increasingly digital society. Around $45 \%$ of EU citizens still do not have basic digital skills with around half of this figure having none at all. In some Member States, a majority of citizens do not go online on a regular basis or cannot function effectively online. They miss out on many life enriching opportunities and economic benefits. This is particularly the case for certain segments of the population including older people, the less educated and those on low incomes. Moreover, there is a need to strengthen confidence in digital by ensuring that citizens are equipped to protect their privacy and security online.

The Internet permeates every aspect of the economy and society and is also becoming an essential element of children's lives. On average, for countries where data are available, less than $0.5 \%$ of 15 year-olds report never having accessed the Internet. Age of first access to the Internet varies largely across countries from $80 \%$ to $30 \%$ in Greece. Greece also shows the strongest difference in uptake between the young and the old. In more focused statistics, participating in social networks Greek users are behind the European average. The same problem is facing the Greek enterprises where the broadband access is lagging the European average.

\subsection{The labour force}

As digitisation spreads to all sectors of the economy, digital skills are increasingly needed for most jobs. Indeed, most jobs already require basic digital skills. In the future this will only increase and it can be argued that all labour force participants need these skills to remain employable and for entrepreneurship. Despite this, around $37 \%$ of the labour force (employed, self-employed and unemployed) in the EU does not have even basic digital skills. The European labour force needs to be re-skilled for its digital future beyond basic digital skills with a view to professional-related digital needs. Special attention should be paid to skills related to security.

Occupations provide another way of looking at changes in employment. Job losses affect different types of workers in different ways, depending on their skills and the type of tasks carried out on the job. According to the OECD (2015), women in nonroutine and routine-intensive occupations tend to suffer proportionally less during crises and to benefit relatively more during expansions. Among the factors that may contribute to explaining these gender-specific patterns are differences in the distribution of employment of men and women in the public and private sectors, industryand-gender specific dynamics such as the marked decline of construction activities (a male-dominated sector), and the specific type of job accomplished (e.g. personal care).

The results from the first OECD Programme for the International Assessment of Adult Competencies (PIAAC) show large differences in computer use at work across countries. The increasing use of ICTs at work requires workers to perform different tasks and to develop complementary skills. On average, intensive use of ICTs at work 
is associated with greater interaction between co-workers and clients, more problem solving, less physical work and higher numeracy. For most tasks, correlations with ICTs tend to decrease with the skill level of the occupation.

Job recovery is becoming more widespread and gaining momentum with unemployment declining in most countries, including those hardest hit by the crisis (OECD, 2015b). According to OECD statistics (2015), youth employment rates remain of particular concern, especially in Europe, with average unemployment rates for younger workers (15-24 years old) at over $20 \%$, rising to above $40 \%$ in Spain, Greece and Italy. Employment growth varied widely for different groups during the recovery, with unemployment rates for women slightly above those for men.

\subsection{ICT professionals}

Digitisation is also leading to increasing demand for ICT professionals in all sectors of the economy. Indeed already more than half of all ICT professionals work outside the ICT sectors in ICT-using industries such as automotive, pharmaceuticals and the like. Employment of ICT professionals has increased by around 1.5 million over the last five years alone. However, supply is not keeping pace with demand and it is expected that by 2020 Europe could have around 756,000 unfilled vacancies for ICT professionals. At the same time, we have almost $20 \%$ youth unemployment in the EU. We need to train more young people for these new digital jobs.

In Greece, despite the fact that the percentage of the ICT sector on GDP is decreasing for the last 5 years, the number of persons employed in the ICT sector as \% of the total employment increased during the same period of time.

\section{Acknowledgments}

This paper was supported by the European Economic Area (EEA: http://eeagrants.org/) Project entitled "e-Women: Innovation and Employability for Women".

\section{References}

[1] Barreto, M.E., Ryan, M.K., and Schmitt, M.T. (2009). The glass ceiling in the 21st century: Understanding barriers to gender equality. American Psychological Association. https://doi.org/10.1037/11863-000

[2] Bebetsos, E. \& Antoniou, P. (2009) "Gender differences on attitudes, computer use and physical activity among Greek university students", The Turkish Online Journal of Educational Technology, Volume 8, Issue 2 ,Article 6, 63-67.

[3] Cross, K.P. \& Steadman, M.H. (1996). Classroom Research: Implementing the Scholarship of Teaching. San Francisco: Jossey_Bass.

[4] Eurostat; http://ec.europa.eu/newsroom/dae/document.cfm?action=display\&doc_id=15823

[5] Felstead, A., Gillie, D., \& Zhou, Y. (2007) Skills at Work, 1986-2006, ESRC Centre on Skills, Knowledge and Organisational Performance (SCOPE). 
[6] Fraillon, J., Ainley, J., Schulz, W., Friedman, T., \& Gebhardt, E. (2014). Students' use of and engagement with ICT at home and school. In Preparing for life in a digital age (pp. 125-166). Springer International Publishing. https://doi.org/10.1007/978-3-319-14222-7 6

[7] Guerrero, L. (2011). Women and leadership. In W. Rowe, \& L. Guerrero (Eds.), Cases in leadership (pp. 380-412). Thousand Oaks, CA: SAFE Publications.

[8] Lohan and Faulkner, (2004). Masculinities and Technologies Some Introductory Remarks, Men and Masculinities, Vol. 6 No. 4, 319-329. https://doi.org/10.1177/1097184X03 $\underline{260956}$

[9] OECD Science, Technology and Industry Scoreboard 2015.

[10] OECD, Annual National Accounts Database and national statistical institutes, June 2015.

[11] OECD, based on Programme for International Assessment of Adult Competencies (PIAAC) Database, June 2015.

[12] OECD, Education Database, July 2015.

[13] OECD, Main Science and Technology Indicators Database, www.oecd.org/sti/msti.htm, and Research and Development Statistics Database.

[14] OECD, PISA 2012 Database, June 2015.

[15] OECD, PISA 2012 Database, Table 5.2.

[16] OECD, Short-Term Labour Market Statistics Database, May 2015.

[17] OECD, Students, Computers and Learning, October 2015.

[18] Puente, S.N. (2008) Fromcyberfeminism to technofeminism: From an essentialist perspective to social cyberfeminism in certain feminist practices in Spain. Women's Studies International Forum 31, 434-440. https://doi.org/10.1016/j.wsif.2008.09.005

[19] Riley, R. (2007, July). Introduction: Technology, jobs and skills. National Institute Economic Review, 201(1), 61-62. https://doi.org/10.1177/0027950107083050

[20] Schein, V.E. (2007) "Women in management: reflections and projections", Women in Management Review, Vol. 22 Iss: 1, pp.6 - 18. https://doi.org/10.1108/09649420 710726193

[21] Stroh, L. K., Brett, J. M., \& Reilly, A. H. (1996). Family structure, glass ceiling, and traditional explanations for the differential rate of turnover of female and male managers. Journal of Vocational Behavior, 49, 99-118. https://doi.org/10.1006/jvbe.1996.0036

[22] Women Entrepreneurs in Europe, DG Enterprise and Industry of the European Commission, published in 2014.

[23] Women Active in ICT Sector, FINAL REPORT, A study prepared for the European Commission, DG Communications Networks, Content \& Technology 2013.

\section{Authors}

Marios A. Pappas (B.Sc., M.Ed.) is a research associate at N.C.S.R. Demokritos, Institute of Informatics and Telecommunications, Net Media Lab, Athens, Greece (email: mpap@iit.demokritos.gr )

Athanasios Drigas is a Senior Researcher at N.C.S.R. Demokritos. He is the Coordinator of Telecoms Lab and founder of Net Media Lab since 1996. From 1985 to 1999 he was the Operational manager of the Greek Academic network. He has been the Coordinator of Several International Projects, in the fields of ICTs, and e-services (e-learning, e-psychology, e-government, e-inclusion, e-culture etc). He has published more than 200 articles, 7 books, 25 educational CD-ROMs and several patents. He has been a member of several International committees for the design and coordina- 
tion of Network and ICT activities and of international conferences and journals. (email: dr@iit.demokritos.gr).

Yannis Papagerasimou (B.Sc., M.Sc.) holds a Bachelor degree in Electronic and Computer Engineering and a Master's degree in Data Communications. He is a research associate at N.C.S.R. Demokritos, Institute of Informatics and Telecommunications, Net Media Lab, Athens, Greece (e-mail: ypapa@iit.demokritos.gr).

Helen Dimitriou, graduated from the department of Philosophy, Pedagogy and Psychology of University of Athens. She also holds a Med in Special Needs \& Inclusive Education from the University of Sunderland. She is currently working as a qualified teacher in secondary education at the Ministry of Education of Greece and is also an external research associate at N.C.S.R. Demokritos, Institute of Informatics and Telecommunications, Net Media Lab, Athens, Greece (lena.dimitriou@yahoo.com).

Maria Giannacourou is an Organizational Psychologist and Human Factors Specialist, currently a Member of the Adjunct Faculty at Hellenic Open University (School of Social Sciences). She holds a B.A. in Psychology from the University of Maryland, USA, an M.Sc. in Industrial Psychology from Hull University, U.K. and a $\mathrm{PhD}$ in Decision Making, Strategic Planning \& Ergonomics from the University of Piraeus (GR). She is an external research associate at N.C.S.R. Demokritos, Institute of Informatics and Telecommunications, Net Media Lab, Athens, Greece (e-mail: mgianna@otenet.gr).

Nadia Katsanou (M.Sc.) holds a Master's degree in Computer Science-Artificial Intelligence. She is a Senior Telecommunications Scientific Expert at the Hellenic Telecommunications and Post Commission and an external associate at N.C.S.R. Demokritos, Institute of Informatics and Telecommunications, Net Media Lab, Athens, Greece (e-mail: nadia.katsanou@gmail.com).

Sofia Papakonstantinou holds a MA Degree in Publishing from LCC University, United Kingdom, a BA Degree in Interdisciplinary Human Studies from University of Bradford, United Kingdom and a Diploma in Special Education from National and Kapodistrian University of Athens. Her current position today is dealing with European Erasmus projects with CRE.THI.DEV, Rafina, Greece (e-mail: spapakon@hotmail.com)

Evangelia Daratsanou (B.Sc,, MA), holds a Bachelor Degree in Business Administration from Athens University of Economics and Business and an MA in Marketing Management from De Montfort University Business School. She is a Business Consultant and a Project Manager in the fields of Entrepreneurship and Innovation with CRE.THI.DEV., Rafina, Greece (e-mail: edaratsanou@gmail.com)

Christina Agoritsa holds a Bachelor degree in Law and is also a graduate of the National School of Public Administration \& Local Government. For the past 10 years she has been senior official of the General Secretariat for Gender Equality (Ministry of Interior), the governmental agency competent to plan, implement, and monitor the implementation of policies on equality between women and men in all sectors (email: xragoritsa@isotita.gr).

Submitted 28 February 2017. Published as resubmitted by the authors 28 March 2017. 